\title{
Envenoming by the Common Krait (Bungarus caeruleus) and Asian Cobra (Naja naja): Clinical Manifestations and Their Management in a Rural Setting
}

\author{
Himmatrao Saluba Bawaskar, MD; Pramodini Himmatrao Bawaskar, MBBS \\ From the Bawaskar Hospital and Research Center, Mahad Dist-Raigad, Maharasahtra, India
}

\begin{abstract}
Objective.-Villagers are commonly poisoned by kraits and cobras in India, and resulting deaths are common. An inadequate understanding of appropriate snakebite treatment often delays proper treatment of those who are bitten. A lack of simple airway management equipment such as resuscitation bags and laryngoscopes compounds the difficulty in treating many patients and increases mortality in neurotoxic (elapid) venom poisoning. This article discusses the clinical signs and symptoms of krait and cobra envenoming and medical intervention in a rural setting.

Methods.-We enrolled 30 subjects of presumed snake envenoming (krait $=23$ cases, cobra $=7$ cases). Details of the bite site, the subject's activities at the time of the bite, local manifestations, systemic involvement, progress of venom poisoning, and subsequent response to treatment were collected on a standard data form. The type of snake was confirmed either by analyzing the killed specimen or by combining clinical findings and identification by the subject or bystanders when presented with preserved specimens.

Results.-Of 23 subjects (11 male, 12 female) bitten by kraits, 2 were deceased upon arrival, 7 died in the hospital, and 14 recovered. Of the 14 survivors, 4 required artificial respirations with a resuscitation bag, antivenom, and anticholinesterase drugs. One had a dry bite. The remaining 9 recovered with supportive treatment only. Of 7 subjects ( 5 male; 2 female) encountering cobras, 2 who had been bitten were deceased upon arrival at the hospital, and 1 died suddenly of an apparent cardiac arrest after seeing a hooded cobra on a road (there was no evidence of a bite site on this individual). Four subjects recovered with antivenon, anticholinesterase drugs, and/or artificial respiration.

Conclusion.-Early administration of antivenom prevents respiratory paralysis after elapid snake bite. Patients with evidence of respiratory insufficiency after neurotoxic venom poisoning require rapid intubation and artificial ventilation. Anticholinestrase agents may help reverse neuromuscular dysfunction caused by elapid envenoming and may accelerate recovery.
\end{abstract}

Key words: envenomation, krait, cobra, snakebite, poisonous snakes

\section{Introduction}

Approximately 10000 to 50000 snakebite-related deaths occur in India each year. ${ }^{1}$ A majority of the deaths are caused by neurotoxic envenoming by kraits and cobras ${ }^{1,2}$ in India's rural population. Snakebite is common in subtropical countries with heavy rainfall and humid climates. ${ }^{3}$ Common venomous snakes found in the Mahad region of India are kraits (genus Bungarus),

Corresponding author: Himmatrao Saluba Bawaskar, MD, Bawaskar Hospital and Research Center, Mahad Dist-Raigad, Maharasahtra, India 402301 (e-mail: himmatbawaskar@rediffmail.com). cobras (genus Naja), and carpet vipers (Echis carinatus) ${ }^{4}$ Kraits are nocturnal, terrestrial snakes that enter human dwellings in search of prey such as rats, mice, and lizards. ${ }^{4}$ The common krait (Bungarus caereulus) is regarded as the most dangerous species of venomous snake in the Indian subcontinent. ${ }^{5}$ A $35 \%$ to $50 \%$ fatality rate attributed to krait bites has been reported from the Mahad region. 6,7 Villagers in this area usually sleep on the floor of their wattle-and-daub houses (Figure 1), which are often surrounded by dense vegetation. ${ }^{4} \mathrm{Al}$ though not vicious by nature, ${ }^{8}$ the krait may strike a person sleeping on the ground if the person accidentally 


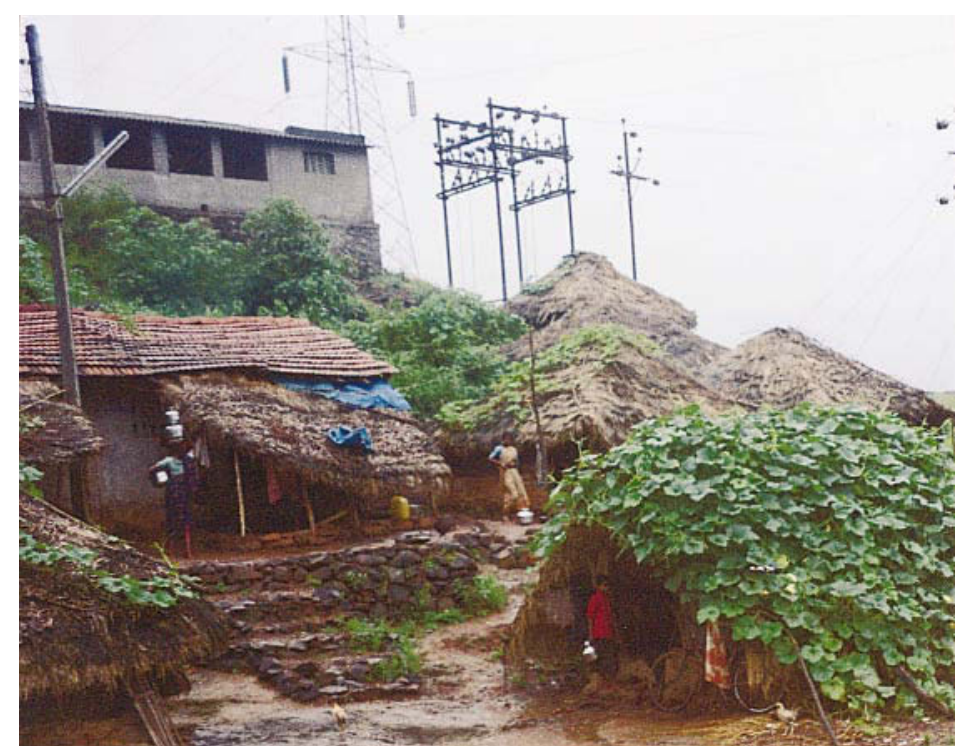

Figure 1. Wattle-and-daub house. A krait can easily find its way into a wattle-and-daub house to hunt for rats, mice, and lizards. Villagers often sleep on the floor of these houses.

touches or rolls over onto the snake. Also, the snake could mistakenly identify an exposed body part as prey. Most bites occur during the cooler months of June to December when snakes may, during the course of their hunting activity, linger in a person's bedding to take advantage of the warmth therein. ${ }^{4,8}$ Vital time is often

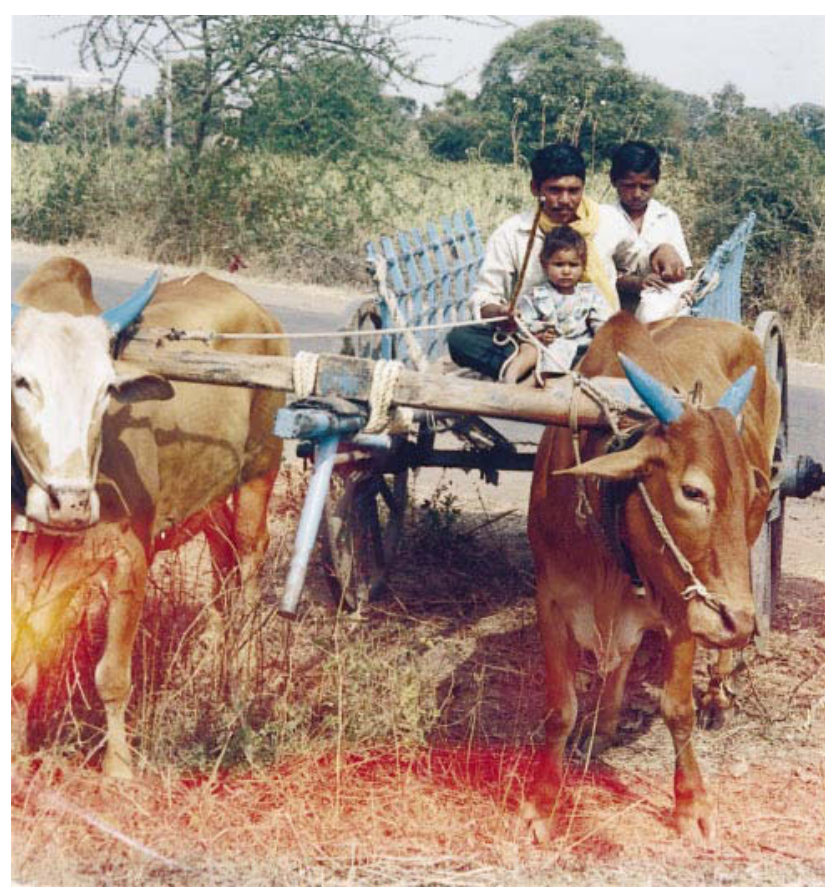

Figure 2. A bullock cart is often the only source of transportation to carry a person to a primary health center during night hours. wasted when, instead of seeking traditional medical treatment, the bitten individual is initially taken to a mantrik or tantrik (a holy person believed to be a Godman and able to remove venom from the body). These local medicine men often use ineffective herbal remedies. When bitten individuals do finally arrive at a medical facility, they often arrive in a bamboo basket or bullock cart (Figure 2), as nighttime transportation is very limited. On the other hand, fear of rapid death after a cobra bite often motivates the majority of persons to go to a hospital much earlier. Cobra bites also tend to occur during daylight hours when transportation is more readily available. ${ }^{9}$ Formal medical care is often provided in primary health centers close to the bitten individual's village. Often the first person to evaluate the patient at the primary health center is a nonphysician medical "officer" who may be inexperienced in the management of snakebites. ${ }^{10}$ Neutralization of circulating venom by early administration of antivenom (AV) may prevent subsequent development of life-threatening respiratory paralysis and possible death. ${ }^{4}$

The major neurotoxic component of krait venom is $\beta$ bungarotoxin, which has high affinity for presynaptic neuromuscular receptors. It irreversibly blocks these receptors and is completely resistant to anticholinesterase treatment. ${ }^{11}$ Nevertheless, apparent improvement with anticholinesterse drugs in cases of neurotoxic envenoming by Bungarus candidus and B caeruleus have been reported. ${ }^{5}$ We report apparent beneficial effects of anticholinesterse drugs in B caeruleus and cobra envenoming. 
Table 1. Age and gender disributions of snakebite cases

\begin{tabular}{|c|c|c|c|c|c|c|c|c|c|c|c|c|}
\hline \multirow[b]{3}{*}{ Age (y) } & \multicolumn{6}{|c|}{ Cobra bite (Naja naja) } & \multicolumn{6}{|c|}{ Krait bite (Bungarus caeruleus) } \\
\hline & \multicolumn{2}{|c|}{ Arrived dead* } & \multicolumn{2}{|c|}{$\begin{array}{c}\text { Died during } \\
\text { treatment }\end{array}$} & \multicolumn{2}{|c|}{ Recovered } & \multicolumn{2}{|c|}{ Arrived dead } & \multicolumn{2}{|c|}{$\begin{array}{c}\text { Died during } \\
\text { treatment }\end{array}$} & \multicolumn{2}{|c|}{ Recovered } \\
\hline & $M$ & $F$ & $M$ & $F$ & $M$ & $F$ & $M$ & $F$ & $M$ & $F$ & $M$ & $F$ \\
\hline$<10$ & 1 & $\ldots$ & $\ldots$ & $\ldots$ & $\ldots$ & 1 & $\ldots$ & $\ldots$ & 1 & 1 & 1 & . \\
\hline $11-20$ & 1 & $\ldots$ & $\ldots$ & $\ldots$ & 1 & $\ldots$ & $\ldots$ & $\ldots$ & 2 & 1 & $\ldots$ & 1 \\
\hline $21-30$ & - & $\ldots$ & $\ldots$ & $\ldots$ & $\ldots$ & 1 & $\ldots$ & $\ldots$ & 1 & $\ldots$ & 2 & 3 \\
\hline $31-40$ & - & $\ldots$ & $\ldots$ & $\ldots$ & $\ldots$ & $\ldots$ & $\ldots$ & $\ldots$ & $\ldots$ & $\ldots$ & 2 & 2 \\
\hline $41-50$ & - & $\ldots$ & 1 & $\ldots$ & $\ldots$ & $\ldots$ & $\ldots$ & 1 & $\ldots$ & $\ldots$ & $\ldots$ & 2 \\
\hline $51-60$ & - & $\ldots$ & $\ldots$ & $\ldots$ & 1 & $\ldots$ & $\ldots$ & 1 & 1 & $\ldots$ & 1 & . . \\
\hline Total & 2 & $\ldots$ & 1 & $\ldots$ & 2 & 2 & $\ldots$ & 2 & 5 & 2 & 6 & 8 \\
\hline
\end{tabular}

*M indicates male; $\mathrm{F}$ indicates female.

\section{Methods}

This was an observational prospective study that included persons who were bitten by kraits and cobras reported over 3 years (2001-2003) at a general hospital in Mahad. This hospital is situated $180 \mathrm{~km}$ south of Mumbai on the Mumbai-Goa highway and has intensive care facilities and experienced doctors researching scorpion and snake envenoming. ${ }^{7}$ The hospital is close to more than 250 villages and receives references of snakebite cases from 4 rural and 18 primary health centers.

The offending snake in each case, if brought with the patient, was identified by hospital staff with zoological photos of Indian snakes. Otherwise, the patient was presented with preserved snake specimens from which the staff could choose. If these methods failed, clinical fea-

Table 2. Distribution of snakebite cases by month of occurrence

\begin{tabular}{lcc}
\hline \multicolumn{1}{c}{ Month } & $\begin{array}{c}\text { Cobra bite } \\
\text { (Naja naja) }\end{array}$ & $\begin{array}{c}\text { Krait bite } \\
\text { (Bungarus caeruleus) }\end{array}$ \\
\hline January & $\ldots$ & $\ldots$ \\
February & $\ldots$ & $\ldots$ \\
March & 1 & $\ldots$ \\
April & $\ldots$ & $\ldots$ \\
May & $\ldots$ & 2 \\
June & $\ldots$ & 2 \\
July & 1 & 7 \\
August & 1 & 3 \\
September & 3 & 6 \\
October & $\ldots$ & 3 \\
November & $\ldots$ & $\ldots$ \\
December & 1 & $\ldots$ \\
Total & 7 & 23 \\
& & \\
\hline
\end{tabular}

tures and circumstantial evidence were used to arrive at a diagnosis of common krait or cobra bite.

Clinical assessment included a detailed history and physical examination. Ptosis, paralysis of external ocular muscles, power of neck flexors and limb muscles, re-

Table 3. Circumstances and anatomic locations of snakebites

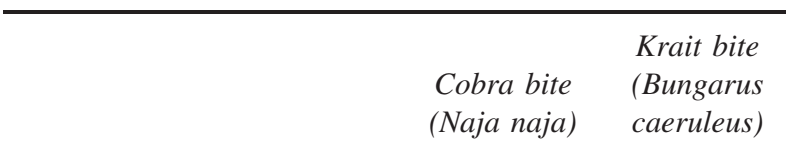

Time of bite

07:00-08:00 hours

16:00-20:00 hours

22:30-05:00 hours

$\begin{array}{cr}3 & \cdots \\ 4 & 1 \\ \ldots & 22\end{array}$

Activity at time of bite

Sleeping on floor bed

Handling file in cupboard

Playing

Walking barefoot at dusk

Cleaning garbage

Handling debris on farm

Site of the bite

Ear pinna

Shoulder

Over scapular region

Axilla

Arm

Fingers

Thigh

Knee

Over calf muscle

Over Achilles tendon

Toes

$\begin{array}{lr}\ldots & 22 \\ \ldots & 1 \\ 3 & \ldots \\ 2 & \ldots \\ 1 & \ldots \\ 1 & \ldots\end{array}$

$\begin{array}{cc}\ldots & 1 \\ \ldots & 1 \\ \ldots & 1 \\ \ldots & 1 \\ \ldots & 2 \\ 3 & 5 \\ \ldots & 2 \\ \ldots & 2 \\ \ldots & 1 \\ \ldots & 2 \\ 4 & 5\end{array}$


Table 4. Signs and symptoms of cobra and krait bites

\begin{tabular}{|c|c|c|}
\hline Clinical effects & $\begin{array}{l}\text { Cobra bite } \\
\text { (Naja naja) }\end{array}$ & $\begin{array}{l}\text { Krait bite } \\
\text { (Bungarus } \\
\text { caeruleus) }\end{array}$ \\
\hline Presence of fang marks & 7 & $\ldots$ \\
\hline $\begin{array}{l}\text { Local swelling with } \\
\text { ecchymosis }\end{array}$ & 7 & 2 \\
\hline $\begin{array}{l}\text { Mild swelling and } \\
\text { tenderness }\end{array}$ & $\ldots$ & 2 \\
\hline $\begin{array}{l}\text { Parethesias, heaviness, prick- } \\
\text { ling sensation in bitten part }\end{array}$ & $\ldots$ & 18 \\
\hline $\begin{array}{l}\text { Pain in abdomen } \\
\text { Ptosis }\end{array}$ & $\ldots$ & 17 \\
\hline Partial & $\ldots$ & 7 \\
\hline Total & $\ldots$ & 12 \\
\hline Blurred vision & 1 & 1 \\
\hline External opthalmoplegia & 1 & 20 \\
\hline \multicolumn{3}{|l|}{ Level of consciousness } \\
\hline Conscious & 1 & 6 \\
\hline Semiconscious & 3 & 7 \\
\hline Comatose & 3 & 8 \\
\hline Vomiting & $\ldots$ & 11 \\
\hline Sweating & $\ldots$ & 3 \\
\hline Bradycardia & $\ldots$ & 1 \\
\hline Hypertension & $\ldots$ & 4 \\
\hline Hypotension & $\ldots$ & 2 \\
\hline
\end{tabular}

spiratory rate, chest expansion, strength of speech (counting), ability to protrude the tongue beyond the teeth margin, level of consciousness, muscle tenderness, local effects at the bite site, and evidence of autonomic dysfunction were all evaluated. Tidal volume was estimated by noting the character and intensity of nasal exhalation of air or by assessing the patient's capacity to count out loud. This was done by a doctor who regularly monitored the patient's progress throughout the hospital stay (periodically during the patient's stay and in response to an initial dose of intravenous neostigmine). Endotracheal intubation and artificial respiration were instituted in patients with pooling of saliva, grade $3 / 6$ muscle power, poor nasal exhalation, cyanosis, semiconscious, bulbar paralysis, or a feeling of suffocation. Polyvalent AV from Haffkine Institute Mumbai was administered intravenously in a standard dose of 10 vials in $200 \mathrm{~mL}$ of saline over 1 hour, followed by 5 vials intravenously over the next 24 hours. Administration of AV was preceded by a subcutaneous dose of adrenaline as prophylaxis against allergic reactions. ${ }^{12,13}$ Relatives of the patients were given instructions as to how to manually ventilate the patient with a resuscitation bag. Ventilation was continued until patients were able to pull out their own endotracheal tubes. Neostigmine, $25 \mu \mathrm{g}$ per kilogram body weight, was infused intravenously for 4 hours until complete recovery of neuromuscular signs and symptoms. Local wound care included antibiotic ad-

Table 5. Management and results

\begin{tabular}{|c|c|c|c|}
\hline Treatment and outcome & Total & $\begin{array}{l}\text { Time interval between bite } \\
\text { and hospitalization }(h)\end{array}$ & Time to recovery or death $(h)$ \\
\hline \multicolumn{4}{|l|}{ Cobra bite (Naja naja) } \\
\hline \multicolumn{4}{|c|}{$\mathrm{AV}^{*}+$ Neostigmine + artifical respiration } \\
\hline Recovered & 3 & $1.5,1.5,1$ & $12,20,18$ \\
\hline Fatal & 1 & 0.5 & 1 \\
\hline \multicolumn{4}{|l|}{$\mathrm{AV}+$ Neostigmine } \\
\hline Recovered & 1 & 2 & 12 \\
\hline Fatal & 2 & 2,1 & . \\
\hline \multicolumn{4}{|c|}{ Krait bite (Bungarus caeruleus) } \\
\hline \multicolumn{4}{|c|}{$\mathrm{AV}+$ Neostigmine + artificial respiration } \\
\hline Recovered & 4 & $2,9,10,9$ & $72,72,6,44$ \\
\hline Fatal & 7 & $3,20,8,8,7,3.5,3$ & $1,6,4,6,4,7.5,1$ \\
\hline \multicolumn{4}{|l|}{$\mathrm{AV}+$ Neostigmine } \\
\hline Recovered & 9 & $2,3,8,3,2.5,3.5,4,2.5,2$ & $24,36,28,40,24,38,48,48,30$ \\
\hline Dry bite $\dagger$ & 1 & 6 & . \\
\hline Arrived dead & 2 & 4,12 & $\ldots$ \\
\hline
\end{tabular}

*AV indicates antivenom.

$\dagger$ No treatment except reassurance and observation (case 4). 


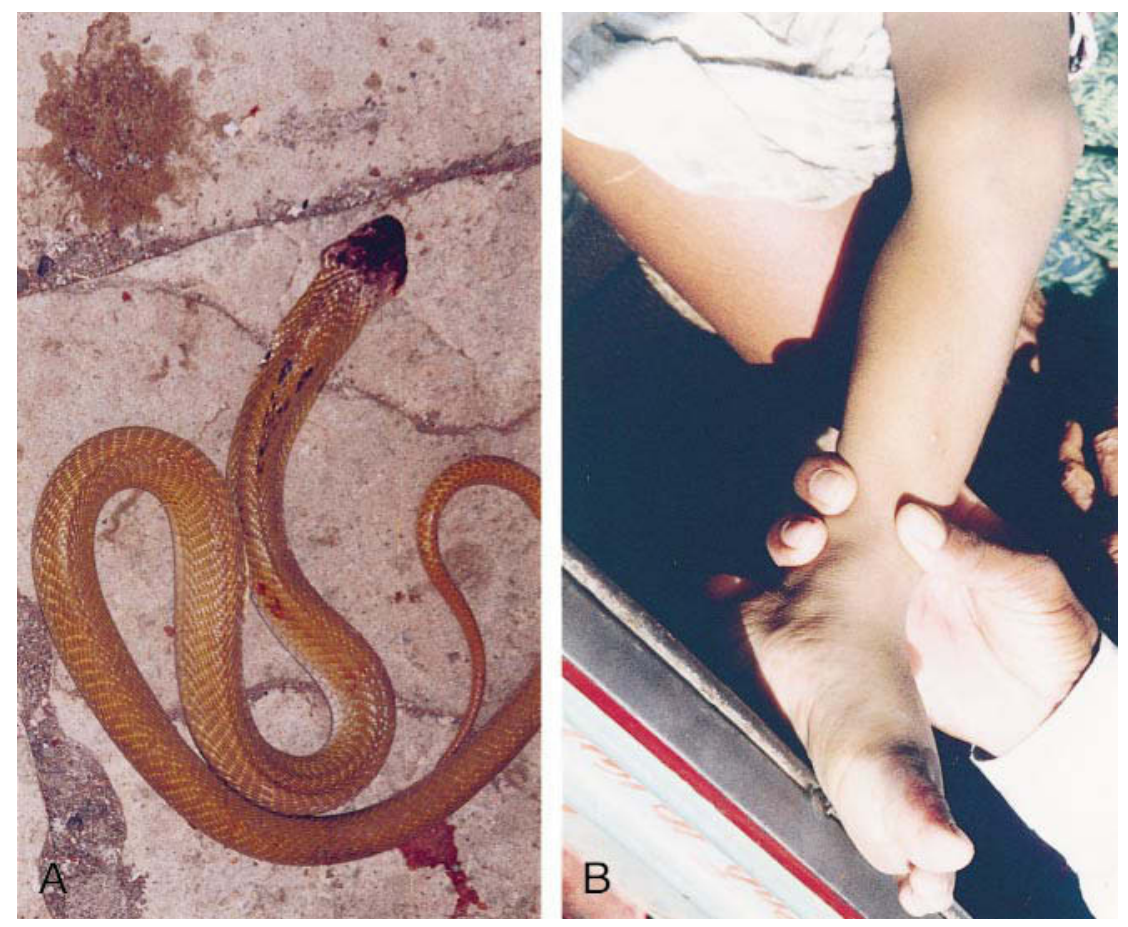

Figure 3. Case 1. A, Killed cobra that was brought in by a relative of the bitten subject. B, Local edema with ecchymosis over the left foot (the site of the bite).

ministration and routine sterile dressings. All patients were immunized for tetanus.

\section{Results}

Thirty patients (23 krait bites, 6 cobra bites, and 1 suspected cobra bite) presented to Mahad General Hospital (Table).

\section{COBRA BITE}

Six subjects were bitten by a cobra between $7 \mathrm{AM}$ and $8 \mathrm{PM}$, and all brought in the dead snake specimen (Figure 3A). Two subjects had local fang marks with edema with ecchymoses; both died within 2 hours of being bitten.

One of the fatalities (Case 1, Figure 3A, B was a 21/2year-old boy who was bitten at $8 \mathrm{AM}$ while playing in front of a house. He had suddenly cried and developed swelling of his left foot, which was the site of the bite (Figure 3B). His parents suspected a snakebite and saw a hole in the ground near the basement of the house where the boy had been playing. When they put kerosene-soaked cotton in the hole, a large cobra came out.

Four cobra-bite patients recovered. The patient in case 7 was brought in deceased. While returning home from work, he saw a hooded cobra passing through grown grass near the road. Soon after, the man felt giddy, be- came very sweaty, and died within 20 minutes. Although a bystander saw the cobra, there were no visible bite marks on the deceased man. This patient had a known history of diabetes, hypertension, and ischemic heart disease.

At 7 AM, a 55-year-old male grocery shop owner (Case 2, Figure 4A, B, C) reached behind a large grain bag to remove some garbage. He felt sudden, severe pain in his right index finger and called his son, who removed the grain bag and found a 4-foot-long cobra and a dead rat. When the cobra was killed, 5 young rats were found in its stomach. The subject experienced severe pain and developed edema and blebs at the bite site (Figure 4A). He reported to the hospital within 2 hours of being bitten. He complained of blurring vision but had no other evidence of neurological dysfunction. His blurred vision improved after administration of 10 vials of AV. At 2 weeks he was noted to have local necrosis and sloughing of the wound, which ultimately required skin grafting. He had no history of diabetes.

\section{KRAIT BITE}

Of 23 subjects (11 males, 12 females) who were bitten by a krait, 22 were bitten while they slept on the floor of their mud and wattle-and-daub houses (Figure 1) between 10:30 PM, and 5 AM. Of these subjects, 2 were 

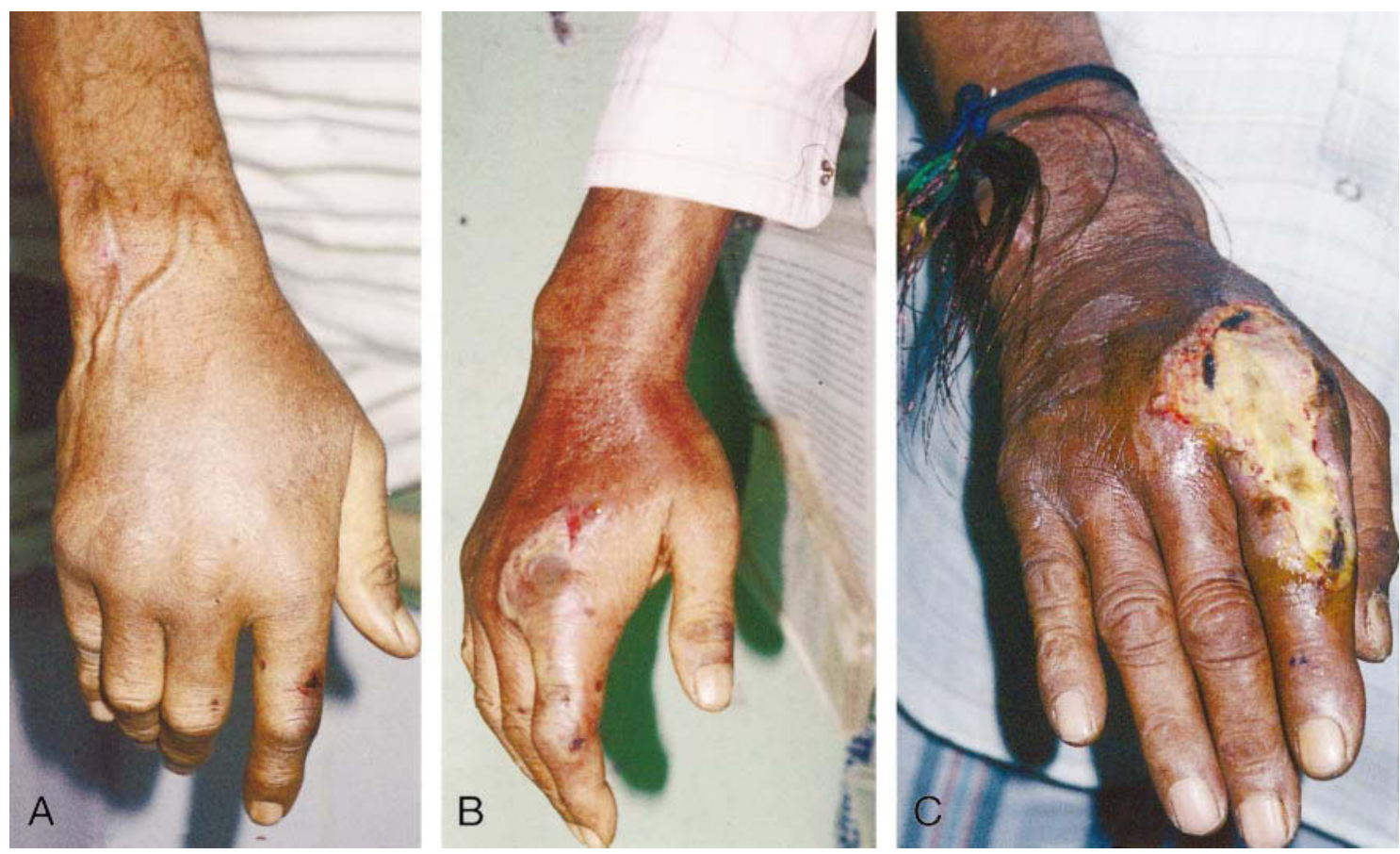

Figure 4. Case 2. A, Two hours after cobra bite: fang marks with blood over right index finger, edema over dorsum of hand. B, Forty-eight hours after cobra bite: local necrosis. C, One week after cobra bite: sloughing of wound with skin necrosis, poor granulation, and unhealthy edges of wound.

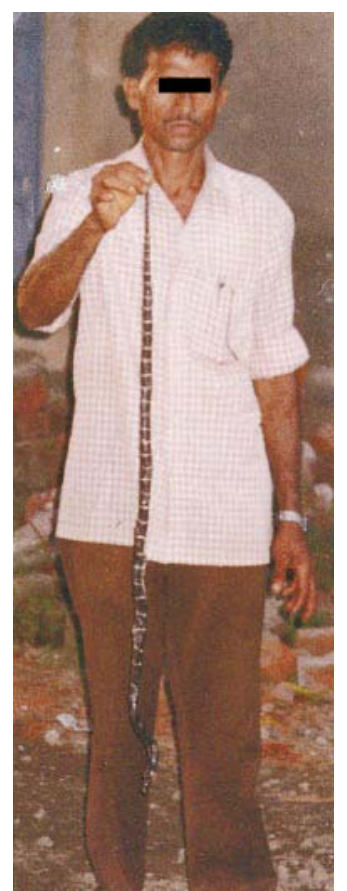

Figure 5. Killed krait (3.5 feet long) brought in by relative of subject in case 5 (see the Table). bitten between 8:30 PM and 11. Two subjects died on the way to the hospital, and 7 died later during treatment. Seven patients recovered after treatment with $\mathrm{AV}$ and neostigmine. The remaining patients had respiratory paralysis and received artificial respiration via a resuscitation bag. Four of these patients recovered. All patients had abdominal pain and mild pain and sensation of heaviness and tingling over the bite site, without obvious local fang marks.

At 4:00 PM, while removing a file from a cupboard at school, a 22-year-old school worker (Case 3) was bitten by a krait, which was later killed. Two and a half hours after the bite, he complained of blurred vision and difficulty swallowing but showed no signs of other neurological symptoms. He recovered after treatment with AV.

A 1/1/2-year-old boy (Case 4) was awakened at 5:00 AM by a painful, pricking sensation on his right foot. A 2.5-foot-long krait was found in his bedding on the floor. The boy was admitted to the hospital and kept under observation. He did not develop any clinical signs suggestive of envenoming except for transient local pain. His condition was monitored for 24 hours, after which he was discharged. This case was likely a dry bite.

A 50-year-old woman (Case 5, Figure 5, Figure 6AG) was bitten by a krait (Figure 5) at 11:30 PM while she was sleeping on the floor. She awoke because of pain in her abdomen. Within 2.5 hours, she was brought to 
the hospital and complained of pain over her right heel and paresthesias and heaviness in her right leg. She then complained of difficulty swallowing and blurred vision, and she developed partial ptosis and external ophthalmoplegia. She recovered after treatment with AV and neostigmine (Figure 6).

A 30-year-old female school headmaster (Case 6) was bitten on her right mid-upper arm at 4:00 AM while sleeping on the floor. There was a large gap between the floor and the lower part of the door. She awoke because of abdominal pain and paresthesias in her right arm. The bite site was swollen and tender, and she developed signs of neurotoxicity. She reported to the hospital 4 hours after the bite and recovered after treatment with AV and neostigmine. The severity of her envenoming may have been limited because the sleeve of her blouse was very tight and her arm was kept below heart level during transportation. Both factors may have helped delay venom absorption and subsequent neurotoxicity.

A 55-year-old-farmer (Case 7) was bitten on his left middle finger by a krait while he was sleeping on his floor bed with his hand below his head. A 3-foot-long krait was found near the bed and was killed. He was brought to the hospital at $7 \mathrm{AM}$. On arrival, he complained of pain and paraesthesias at the bite site. There was mild swelling and local hemorrhagic spots at the site. While being transferred to his first floor hospital bed, he refused wheelchair assistance, preferring instead to walk a distance that include 1 flight of stairs. Soon after arriving at his bed, however, he developed ptosis, external ophthalmoplegia, and complained of difficulty breathing and swallowing. He was given AV, neostigmine, and oxygen, and recovered completely in 30 hours.

\section{Discussion}

Envenoming by Asian cobras (Naja naja) can produce a variety of clinical effects. Severe local tissue necrosis at the bite site without neurotoxicity was seen in case 2 (Figure 4B). ${ }^{14,15}$ Antivenom did not prevent the local tissue necrosis. ${ }^{16}$ Neostigmine reversed neurotoxicity in 4 cases. The cobra neurotoxin, $\alpha$-bungarotoxin, reversibly blocks postsynaptic acetylcholine receptors. ${ }^{11}$ Local edema and ecchymosis at the bite site develops rapidly because of cytolysis, hyaluronidase (spreading factor), and anticoagulant effects of the venom. ${ }^{17}$ Antihistamines may antagonize the action of hyaluronidase and could help reduce edema and subsequent spread of venom. ${ }^{18}$ Local signs with neurological manifestations helped differentiate cobra bites from krait bites, which cause minimum or no local findings. ${ }^{4-7}$

Many variables determine the severity of any partic- ular snakebite case. No age groups are immune to krait bites. Young, inexperienced children may not be fearful of being bitten by a snake. Because of children's smaller body surface area and lower circulating blood volumes, pediatric mortality may be higher than in adults. ${ }^{18}$ When a snake bites after killing its prey or when it has a full stomach, the quantity of venom injected is not necessarily altered. ${ }^{5}$ Sudden withdrawal of a bitten hand might result in less venom injection and less severe poisoning (case 2).

Kraits move freely in and out of houses to hunt during the night. ${ }^{4}$ Seventeen $(85 \%)$ of our cases were reported between midnight and 5:00 AM during the heavy rains in June through October, when snake and rodent holes and burrows often fill with water. In our previous and present reports, all individuals who were bitten by a krait were Hindus, ${ }^{4}$ many of whom, particularly the females, sleep on the floors of their homes. Muslims, on the other hand, irrespective of their financial status, usually sleep on cots.

Kraits may inject more venom at night because they are nocturnal predators. Accidental daytime or early morning krait bites (cases 3 and 4) often involve less severe envenoming.

These bites occurred at night when transport facilities are poor, and the resulting delayed hospitalization increases fatalities. ${ }^{4-7}$ Thirty percent of the fatalities are due to the delayed (up to 6 hours) administration of AV, during which the venom has already reached the receptors and cannot be neutralized by circulating AV. ${ }^{11}$

One of the major components of krait venom is $\beta$ bungarotoxin, a presynaptic acetylcholine receptor blocker. ${ }^{11}$ The small, molecular size of krait venom components facilitates rapid absorption into the circulation from the bite site. Wearing restrictive clothing, immobilizing the limb, and keeping the bite site below heart level may have prevented rapid venom absorption and development of respiratory paralysis in case 6. Prehospital placement of an elastic bandage wrap and splint may delay venom absorption after some snakebites. ${ }^{19}$ Although restricting venom to the bite site might worsen local destruction of tissues, ${ }^{2}$ given the risk of severe systemic toxicity after a krait bite, tight clothing above the bite or a tourniquet applied in the field should not be released (case 6) unless a full dose of AV is available and ready to be administered. , $^{2,17}$

Extraocular muscles are quite sensitive to neuromuscular blockade by snake venom ${ }^{11}$; each motor neuron innervates only 6 to 12 muscle fibers in eye muscles, compared with large proximal limb muscles where the ratio may reach $1: 2000 .^{20}$

Vomiting, sweating, bradycardia, and hypertension 

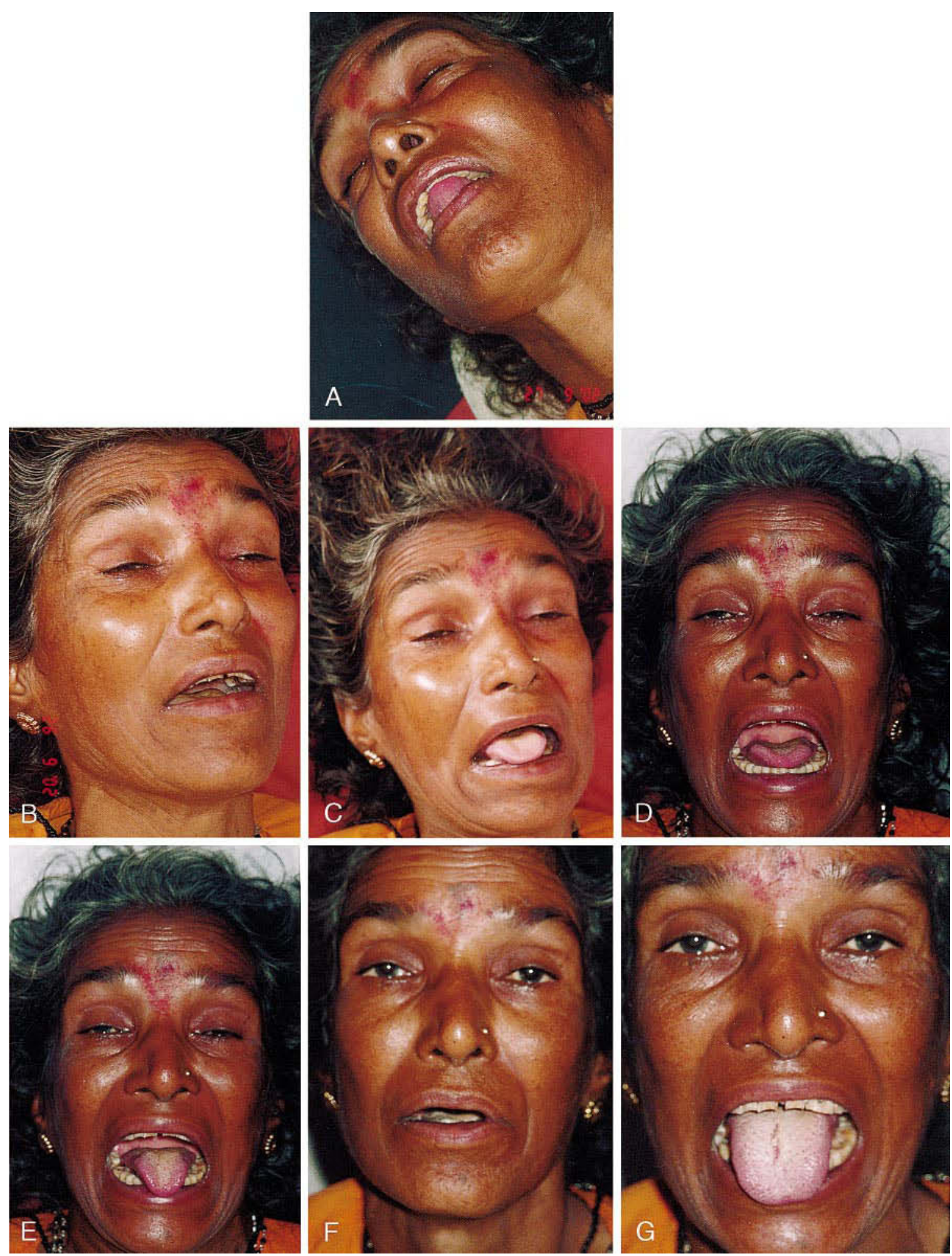

Figure 6. Subject in case 5 -response to antivenom and neostigamine (given at $\mathrm{T}_{0}$ ). A, $\mathrm{T}_{0}(2.5$ hours after bite): semiconscious, bilateral complete ptosis. $\mathbf{B}, \mathrm{T}_{0}+20$ minutes: partial ptosis, conscious, unable to protrude tongue. $\mathbf{C}$, $\mathrm{T}_{0}+60$ minutes: ptosis reduced, able to protrude tongue. $\mathbf{D}, \mathrm{T}_{0}+12$ hours: ptosis reduced, wide opening of mouth. $\mathbf{E}, \mathrm{T}_{0}+24$ hours: ptosis reduced $>50 \%$; cornea is uncovered, able to open the mouth widely and fully protrude the tongue. $\mathbf{F}, \mathrm{T}_{0}+30$ hours: ptosis reduced, only $20 \%$ of cornea is covered, improvement in expression. G, $\mathrm{T}_{0}+36$ hours: $10 \%$ of cornea is covered, otherwise completely recovered. 
have been reported and suggest autonomic stimulation by venom. ${ }^{8}$

The major concern in most cases of elapid envenoming is the sudden development of respiratory paralysis. ${ }^{2,21}$ A bitten individual with minimal neuroparalytic signs or symptoms should be kept in a semiprone position to avoid aspiration, or an endotracheal tube should be inserted to prevent aspiration. ${ }^{22}$ Artificial respirations in individuals with respiratory failure or paralysis can be life saving. ${ }^{4}$

The precise beneficial effects of AV in treating cobra bites has been questioned, for patients often do well when they receive anticholinesterse drugs and mechanical ventilation without the use of AV. ${ }^{9,19}$ Ten vials (or $100 \mathrm{~mL}$ ) of AV administered for 1 hour and 5 vials for 24 hours by slow intravenous drip allows neutralization of venom slowly released from the site of the bite and absorbed into the circulation. ${ }^{2,23}$ Repeat dosing is required because the half life of venom is more than 72 hours, whereas the half life of AV is 26 to 95 hours. ${ }^{23,24}$ No significant difference was noted between the duration of ventilation and the dose of AV administered. Higher doses of AV have no effect in reversing respiratory failure in instances of common krait bite. ${ }^{4,8}$

Iberitoxin, a calcium-dependent potassium channel blocker of venom from the Indian red scorpion (Mesobuthus tamulus), might help reverse the neuroparalysis caused by $\beta$-bungarotoxin. ${ }^{7}$

Snakebite is an agricultural-occupational hazard and is a major public health problem in India. Appropriate training of medical officers regarding signs, symptoms, and indications for AV should be arranged at the district level. Practical training in endotracheal intubation technique in an endemic area of elapid bites is essential. ${ }^{2}$ Villagers who live in wattle-and-daub houses should be educated about the biting patterns of the common krait and how the routine use of bamboo cots with mosquito netting will help prevent malaria, scorpion stings, and krait bites alike. ${ }^{25}$

\section{Acknowledgment}

We would like to acknowledge Dr M. S. Pradhan, scientist and officer in charge of the Zoological Survey of India for identifying the snake specimens.

\section{References}

1. McNamee D. Tackling venomous snake bite worldwide. Lancet. 2001;357:1680.

2. Warrell DA. The clinical management of snake bites in Southeast Asian region. Southeast Asian J Trop Med Public Health. 1999;30(suppl):1-67.
3. Banerjee RN. Poisonous snakes, their venoms, symptomatology and treatment progress in clinical medicine. In: Ahuja MMS, ed. Progress in Clinical Medicine in India. Vol 2. New Delhi, India: Arnold Heinemann; 1978:136179.

4. Bawaskar HS, Bawaskar PH. Profile of snakebite envenoming in western Maharashtra India. Trans $R$ Soc Trop Med Hyg. 2002;96:79-84.

5. Theakston RDG, Phillips RE, Warrell DA, et al. Envenoming by the common krait (Bungarus caeruleus) and Sri Lanka cobra (Naja naja naja): efficacy and complications of therapy with Haffikine antivenom. Trans $R$ Soc Trop Med Hyg. 1990;84:301-308.

6. Bawaskar HS, Bawaskar PH. Snake bite. Bombay Hosp J. 1992;34:190-194.

7. Bawaskar HS, Bawaskar PH. Envenoming by scorpions and snakes (Elapidae), their neurotoxins and therapeutics. Trop Doct. 2000;30:23-25.

8. Kulartane SAM. Common krait (Bungarus caeruleus) bite in Anuradhapura, Sri Lanka: a prospective clinical study, 1996-98. Postgrad Med J. 2002;78:276-280.

9. Bomb BS, Roy S, Kumawat DC, Bharjatya M. Do we need antisnake venom (ASV) for management of elapida ophitoxaemia? JAPI. 1996;44:31-33.

10. Bawaskar HS, Bawaskar PH. Call for a global snake-bite control and procurement of funding [letter]. Lancet. 2001; 357:1132-1133.

11. Watt MD, Theakston DRG, Hayes CG, et al. Positive response to endrophonium in patients with neurotoxic envenoming by cobras (Naja naja philippinensis). $N$ Engl $J$ Med. 1986;315:1444-1448.

12. Premawardherna AP, De Silva CE, Fonseka MMD, Gunatilake SB, De Silva HJ. Low dose of sub-cutaneous adrenaline to prevent acute adverse reaction to antivenom serum in people bitten by snakes: randomized, placebo controlled trial. Br Med J. 1999;318:10410-10413.

13. Bawaskar HS, Bawaskar PH. Aphasia in a farmer after viper bite [letter]. Lancet. 2002;360:1703.

14. Reid HA. Cobra bites. Br Med J. 1964;ii:540-545.

15. Warrell DA, Greenwood BM, Davidson N McD, Ormerod LD, Prentice CRM. Necrosis, haemorrhage and complement depletion following bites by spitting cobra (Naja nigricollis). QJM. 1976;45:1-22.

16. Ponchanugool C, Limthongkull S, and Meemano K. Clinical features of 37 non-antivenin treated neurotoxic snake bite patients. In: Gopalakrishnakone P, Tan CK, eds. Progress in Venom and Toxin Research. Singapore: Faculty of Medicine, National University; 1987:46-51.

17. Warrell DA. Venous bite and stings. Med Int. 1992;45:2733.

18. Mathew JL. Snakebite. Pediatr Today. 1999;ii:36-44.

19. Sutherland SK, Coulter AR, Harris RD. Ratiolisation of first-aid measures for elapid snake bite. Lancet. 1979; I: 183-186.

20. Mycology. In: Williams PL, Warwick R. Gray's Anatomy. 36th ed. Philadelphia, PA: WB Saunders; 1980: 506-519.

21. Jacob J. Snake Venom Poisoning. The Problem, Diagnosis 
and Management of Snake Venom Poisoning. Bombay: Bombay Varghase Publishing House; 1990.

22. Bawaskar HS. Uses of errors - mistakes are lessons of the past. Lancet. 2003;361:59.

23. Ariaratnam CA, Meyer WP, Eddleston PM, et al. A new monospecific ovine fab fragment antivenom for treatment of envenoming by the Lankan Russell's viper: a prelimi- nary dose-finding and pharmacokinetic study. Am J Trop Med Hyg. 1999;61:259-265.

24. Reid A, Then PC, Chan KE, Baharom AR. Clinical effects of bites by Malayan viper (Ancistrodon rhodostoma). Lancet. 1963;2:617-621.

25. Bawaskar HS, Bawaskar PH. Malaria vaccine [letter]. Lancet. $1996 ; 348: 1329$. 